\title{
Non-healing 'diabetic' ulceration which turned out to be a lentiginous melanoma: a case from a diabetic foot clinic
}

\author{
Peter Novodvorsky, ${ }_{1}^{1,2}$ Muhammad Fahad Arshad, ${ }^{2}$ Susan Heyes, ${ }^{2}$ Rajiv Gandhi ${ }^{1,2}$
}

'Department of Oncology and Metabolism, University of Sheffield, Sheffield, UK ${ }^{2}$ Department of Diabetes and Endocrinology, Sheffield Teaching Hospitals NHS Foundation Trust, Sheffield, UK

\section{Correspondence to}

Dr Peter Novodvorsky, p.novodvorsky@sheffield.ac.uk

Accepted 18 December 2018

\section{DESCRIPTION}

There are currently 425 million of people with diabetes worldwide ${ }^{1}$ and diabetic foot disease affects approximately $6 \%$ of them..$^{2}$ Any skin lesion in a person with a history of diabetes should be, however, reviewed with an open mind and with awareness of possible differential diagnoses. This becomes particularly relevant in cases with an apparent discrepancy between the duration of diabetes, level of metabolic control and presence/ absence of other microvascular complications on one side and presence of a non-healing 'diabetic' ulceration on the other.

We report a case of a 48-year-old man with type 2 diabetes who was referred by his general practitioner to a podiatry-led foot clinic with a blister over the plantar aspect of the first metatarsophalangeal joint of his left foot. At the time of the referral, his diabetes was managed with diet and he had a very good level of metabolic control (Haemoglobin A1c $31 \mathrm{mmol} / \mathrm{mol}$ ). He also had a history of liver cirrhosis secondary to alcoholic liver disease, hepatocellular carcinoma treated with radio frequency ablation 4 years ago and arterial hypertension. At the time of the initial review, the lesion was reported to be surrounded by patches of dark brown discolouration which was thought to be resorbed haematoma, but with no signs of infection or callus. He had bilaterally present peripheral arterial pulses and the neurological examination of his feet was normal to all modalities. An advice for pressure offloading with a hexagonal shoe was given and he was referred to orthotics for provision of custom-made insoles and for footwear review.

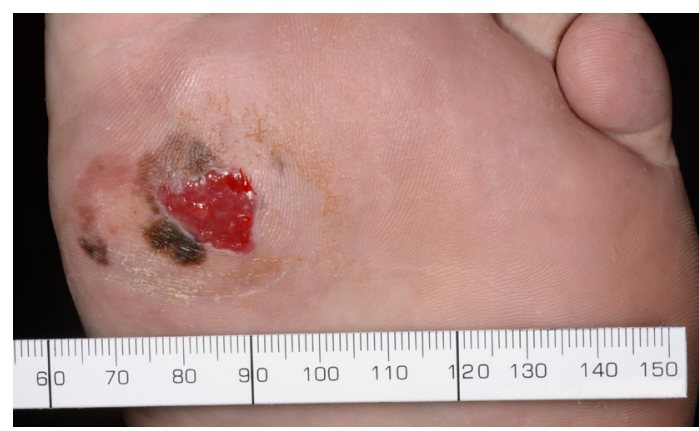

Figure 1 Photograph of the acral lentiginous melanoma localised over the first metatarsal head on the sole of the left foot. Apart from the non-healing ulceration, patches of dark brown and black pigmentation can be noted.

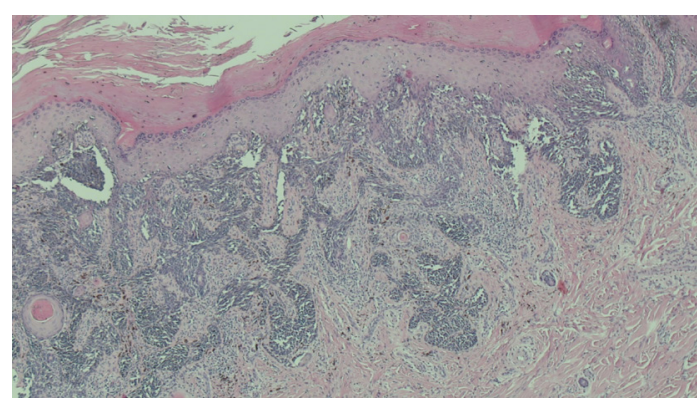

Figure 2 Histopathological image shows primary invasive cutaneous malignant melanoma. $\mathrm{H} \& \mathrm{E}$ stain, $\mathrm{x} 20$.

Pressure offloading was complicated by the character of his job (works at a production line) and inability to take time off work. Three months later, the ulceration was still not healing and a decision was made for him to undergo a period of more strict pressure offloading with a Bohler walker and a cast during his annual leave period. Two weeks later, the lesion was reported as healed and Bohler walker could be removed. He was given advice for further pressure offloading and was asked to report back to the clinic in case of re-ulceration. Two weeks later, he reattended the foot clinic with a recurrence of ulceration. The non-healing character of the lesion with irregular patches of dark brown and black pigmentation (figure 1), together with the fact that the patient reported a recent left toe amputation due to malignant melanoma in his brother prompted an immediate referral to dermatology with a suspicion of malignant melanoma.

Punch biopsy confirmed a primary invasive cutaneous malignant melanoma with estimated Breslow index of $2-3 \mathrm{~mm}$, mitotic index of $2 / \mathrm{mm}^{3}$ and Clark level 4 (figure 2). He subsequently underwent a wide excision of the melanoma and resurfacing with graft and skin substitute as well as sentinel node biopsy in the left groin. The report of sentinel node biopsy was not available at the time of submission of this manuscript.

\section{Patient's perspective}

Throughout the term with the lesion on my foot it was virtually pain free, which kind of diluted the severity of what was going on with my foot so I was quite happy to listen to what the medical staff was telling me. Had I been in more pain, maybe more questions would have been asked leading to a quicker diagnosis. 


\section{Learning points}

Any skin lesion in a person with a history of diabetes should be reviewed with an open mind and with awareness of possible differential diagnoses.

- This is especially the case in situations where there is a discrepancy between the duration of diabetes, level of metabolic control and absence of other microvascular complications on one side and presence of a non-healing 'diabetic' ulceration on the other.

- Irregular patches of brown and black discolouration/ pigmentation in any skin lesion should raise a suspicion of malignant melanoma
Acknowledgements The authors are thankful to Ali Al-Omari and Nick J Tiffin from Sheffield Teaching Hospitals NHS Foundation Trust, Sheffield, UK for provision of the histopathological image.

Contributors PN wrote the manuscript. MFA, SH and RG attended to the patient and reviewed the manuscript.

Funding The authors have not declared a specific grant for this research from any funding agency in the public, commercial or not-for-profit sectors.

Competing interests None declared.

Patient consent Obtained.

Provenance and peer review Not commissioned; externally peer reviewed.

\section{REFERENCES}

1 International Diabetes Federation. Diabetes atlas IDF. 8th edn Brussells. Belgium: International Diabetes Federation, 2017.

2 Mishra SC, Chhatbar KC, Kashikar A, et al. Diabetic foot. BMJ 2017;359:j5064.

Copyright 2018 BMJ Publishing Group. All rights reserved. For permission to reuse any of this content visit

https://www.bmj.com/company/products-services/rights-and-licensing/permissions/

BMJ Case Report Fellows may re-use this article for personal use and teaching without any further permission.

Become a Fellow of BMJ Case Reports today and you can:

- Submit as many cases as you like

- Enjoy fast sympathetic peer review and rapid publication of accepted articles

- Access all the published articles

Re-use any of the published material for personal use and teaching without further permission

For information on Institutional Fellowships contact consortiasales@bmjgroup.com

Visit casereports.bmj.com for more articles like this and to become a Fellow 